\title{
Volume Breast Ultrasound in a Patient with Breast Lump
}

\author{
S A RUPA $^{\mathrm{a}}$, K NAHAR ${ }^{\mathrm{b}}$, S SULTANA $^{\mathrm{c}}$
}

(J Bangladesh Coll Phys Surg 2018; 36: 41)

A 57 years female patient presented to our breast clinic with a painless palpable mass in her right breast for 2 months.

On examination, a mass was felt in her right breast at 9 to 10 O'clock position which was not fixed with the skin. No palpable axillary lymphnode was found . Patient was advised for breast ultrasound .

$2 \mathrm{D}$ breast ultrasound revealed an ill defined hypoechoic area with cluster of microcysts (size about $43 \mathrm{~mm} \times 16$ $\mathrm{mm}$ ) at 9 to 11 O'clock position of right breast and USG diagnosis was Low suspicious for malignant lesion( BIRADS 4a).No axillary lymphadenopathy was seen (Figure 1).

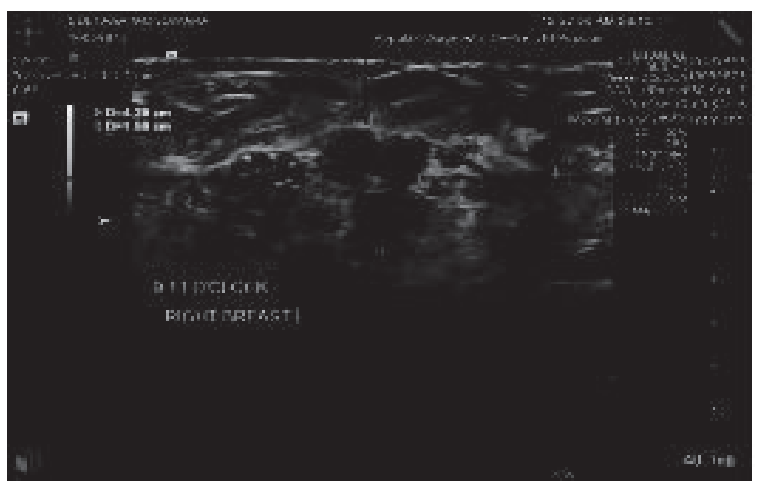

Fig.1 : 2D Ultrasonogram of right breast

Then patient was undergone volume breast ultrasound. Volume breast imaging showed size of the mass measuring about $95 \mathrm{~mm} \times 90 \mathrm{~mm}$ with cluster of microcysts, ill-defined margin, thick walled dilated ducts, microcalcifications and USG diagnosis was Highly suspicious for malignant lesion ( BIRADS 5 ) (Figure 2,3,4).

a. Dr. Sharmin Aktar Rupa, Associate Professor, Department of Radiology and Imaging, Popular Medical College, Dhaka.

b. Dr. Kamrun Nahar, Associate Professor, Department of Radiology and Imaging, Bangladesh Medical College, Dhaka.

c. Prof. Salma Sultana, Department of Surgery, Dhaka Medical College and Hospital, Dhaka.

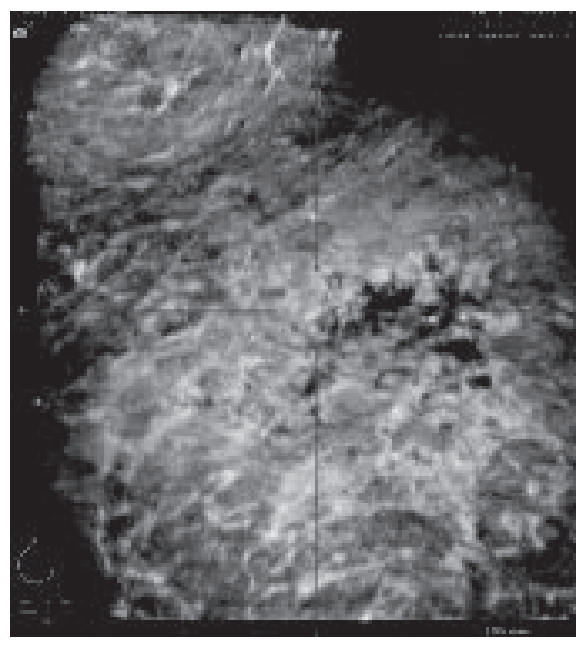

Fig.-3: Volume Breast USG (transverse image)

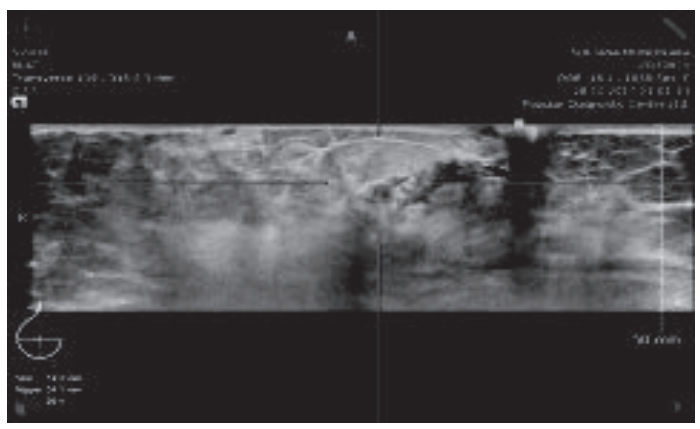

Fig.-2: Volume Breast USG (coronal image)

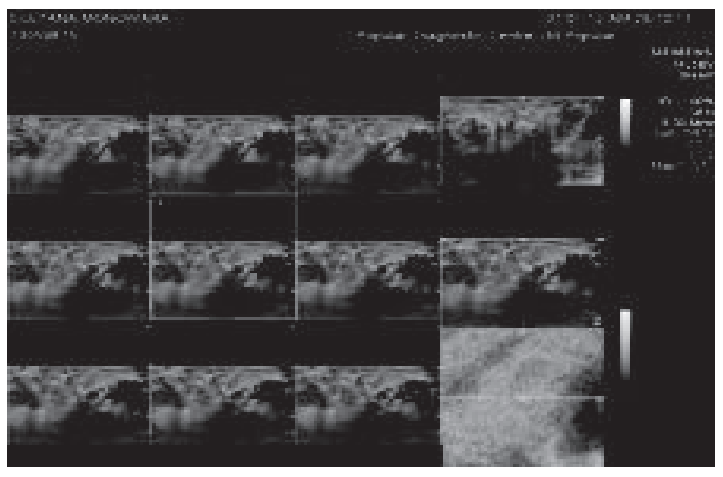

Fig.-4: Volume Breast USG (cross sectional image)

Core biopsy revealed ductal cell carcinoma. 